\title{
Chronic Poverty and Poverty Dynamics: Resolving a Paradox in the Normative Basis for Intertemporal Poverty Measures.
}

\author{
Natalie Naïri Quinn*
}

May 2017

\begin{abstract}
There is a paradox in the normative foundations for chronic and intertemporal poverty measurement. Measures that reflect particular aversion to chronicity of poverty cannot also reflect particular aversion to fluctuations in the level of poverty when poverty is intense, yet good arguments are made in favour of each of these properties. I argue that the paradox may be explained if the poverty analyst implicitly predicts that an individual observed to experience persistent poverty will continue to experience poverty when unobserved. The paradox may then be resolved by separating the normative exercise of evaluation, applying a measure that reflects particular aversion to fluctuations, from a positive exercise of modelling and prediction. This proposal is illustrated by application to panel data from rural Ethiopia, covering the period 1994-2004. Several dynamic models are estimated and a simple model with household-specific trends is found to give the best predictions of future wellbeing levels. Appropriately normalised measures of intertemporal poverty are applied to the predicted and observed trajectories of wellbeing and results are found to differ substantially from naïve application of the measures to observed periods only. While similar results are obtained by naïve application of the measures that embody particular aversion to chronicity, separation of the normative and positive exercises maintains conceptual clarity.
\end{abstract}

*Department of Economics and St John's College, University of Oxford. natalie.quinn@economics.ox.ac.uk. 


\section{Introduction and Motivation}

The increasing availability of socioeconomic panel or longitudinal data collected in both developing and developed countries ${ }^{1}$ has stimulated advances in two branches of welfare economics. The first is empirical research about the dynamics of wellbeing and poverty at the individual or household level. Understanding the dynamic processes driving the evolution of wellbeing over time is essential for the design of policies whose objectives are to tackle the problem of poverty. The second is the normative evaluation of poverty over time. Several measures of 'chronic' and 'intertemporal' poverty have been proposed in the recent literature and the normative judgements that they embody have been explored.

When households experience fluctuations in wellbeing, repeated application of a crosssectional or static poverty measure ${ }^{2}$ both embodies a particular set of normative judgements and discards relevant information. To take a very simple example, suppose that the headcount measure of poverty in a population is stable at $30 \%$ when measured on an annual basis. It could be that the same individuals are poor every year, or that different individuals move in and out of poverty, often described as 'churning'. Whether or not to regard these two situations as equivalent is a normative judgement that should be considered explicitly by the poverty analyst.

The literature in this field is developing rapidly; several authors have developed indices that aggregate individual-level indicators of wellbeing over an extended period of time to measure chronic or intertemporal poverty. (Some also aggregate over individuals to give a social measure, but the main innovation is in the individual-level measurement.) The various measures differ in the way that they order alternative trajectories of wellbeing and thus embody different normative judgements about the relative undesirability of the trajectories. For example, the measures suggested by Foster (2009), Gradin et al. (2011) and Bossert et al. (2012) are particularly sensitive to persistence or duration of poverty or deprivation, and are thus well described as chronic poverty measures. The measures suggested by Foster \& Santos (2013) and Porter \& Quinn (2013) are sensitive to transient depth of poverty and thus fluctuation, with that suggested by Porter \& Quinn (2013) being particularly sensitive to extremely severe deprivation, allowing for less compensation between periods, the deeper the degree of poverty. It turns out (Porter \& Quinn 2012) that this property is incompatible with sensitivity to persistence of poverty. Good arguments are made in favour of each of these properties, so their apparent conflict deserves further attention and exploration.

Returning to empirical research on poverty dynamics, questions that have been addressed include the identification of factors that influence the probability of moving into and out of poverty, the existence and nature of poverty traps and the determinants of escape from poverty. The literature consistently finds that across many times and places some households remain poor persistently whilst others move into and out of poverty. These two groups are commonly described as chronically and transiently poor, respec-

\footnotetext{
${ }^{1}$ Baulch (2011) lists 65 panel datasets in 39 developing and transitional countries. Notable examples at household level in a rural developing country context include ICRISAT's Village Level Studies, whose subjects were surveyed annually from 1975-1976 to 1983-1984 with follow-up surveys in 2001-2006, and the Ethiopia Rural Household Survey (ERHS) whose subjects were surveyed twice in 1994 and in 1995, 1997, 1999, 2004 and 2009.

${ }^{2}$ Examples include the dollar-a-day headcount used for international comparisons (Chen \& Ravallion 2008), now updated to $\$ 1.90$ in 2011 PPP terms as the headline poverty measure in the Sustainable Development Goals (Ferreira et al. 2015), and inequality-sensitive measures such as the squared poverty gap measure $P_{2}$ (Foster et al. 1984) widely used in applied academic research.
} 
tively.

Baulch \& Hoddinott (2000) reviewed thirteen panel studies in developing countries, which demonstrated consistently that a significant proportion of households experience transient poverty, in most cases a larger proportion than the proportion of households that experience poverty in all of the study periods. In particular, Gaiha \& Deolalikar (1993) find that $87.8 \%$ of the ICRISAT households have incomes below the poverty line in at least one period of the survey, $61.3 \%$ in at least five of the nine periods while just $21.8 \%$ do in all nine periods. Porter (2008), analysing all rounds of the ERHS at that date except the second, finds that $63.7 \%$ of the households have per-adult-equivalent consumption below the poverty line in at least one round, $21.0 \%$ in at least three while only $2.6 \%$ do in all five rounds. While some observed fluctuations in wellbeing may be ascribed to measurement error, several of the studies surveyed by Baulch \& Hoddinott demonstrate that income shocks have explanatory power for consumption, suggesting that measurement error cannot be the only source of the observed fluctuations. ${ }^{3}$

Many of the studies surveyed by Baulch \& Hoddinott (2000) model poverty dynamics and economic mobility, while Dercon \& Shapiro (2007) review the findings of the more recent literature. Many of the studies reviewed by Dercon \& Shapiro find that education and household assets are associated with positive economic mobility while income and health shocks have persistent negative effects, although not all of these results have a clear causal interpretation. Fluctuations in wellbeing are associated with an absence of insurance markets; Dercon (2004b) contains both theoretical and empirical analyses of this relationship and evidence for a causal impact on persistence of poverty. Some studies, notably Carter \& Barrett (2006), combine elements of both positive and normative analysis. Given the impossibility of perfect measurement or knowledge of the future, incorporating elements of positive modelling is necessary to conduct normative evaluation when the poverty analyst cares about future wellbeing as well as, or rather than, past wellbeing. Such studies have not always made explicit the distinction between normative judgements and positive models or assumptions that are applied.

Returning to the conflict between particular aversion to chronicity of poverty and particular aversion to fluctuations in the level of poverty when poverty is intense, in this paper I suggest and explore a potential resolution. The poverty analyst (who is making the normative judgement) may really be concerned about the individual's trajectory of wellbeing or experience of poverty over an extended period of time or their whole lifetime, not just the particular time periods in which they are observed. As deprivation and poverty are generally understood to persist over time and even over generations, it is possible that a poverty analyst applying a persistence-sensitive measure is implicitly using persistence of poverty within an extended period of observation to proxy for future or lifetime experience. The normative exercise of evaluation has become confounded with a positive exercise of prediction. It follows that, where suitable data is available, a better approach would be to draw on the literature modelling welfare and poverty dynamics to build an empirical model of future or lifetime wellbeing for the individual. A normative measure of intertemporal poverty may then be combined with the predictions of the positive model to measure poverty over time in a way that reconciles the two desirable but conflicting properties.

The paper proceeds as follows. In section 2 I review some of the recently-suggested

\footnotetext{
${ }^{3}$ Townsend (1994) and Dercon \& Krishnan (2000) show that households in the ICRISAT and ERHS villages, respectively, achieve partial but not complete consumption smoothing in the face of income shocks.
} 
intertemporal and chronic poverty measures and explore the conflicting properties. In section 3 I describe the consumption data from the Ethiopian Rural Household Survey that will be used to illustrate the proposed approach. In section 4 I apply several alternative approaches to model explicitly the evolution of household wellbeing over the duration of the study. In section $5 \mathrm{I}$ apply the intertemporal poverty measures to the modelled data and discuss the results. Section 6 concludes.

\section{Chronic Poverty Measures and the Paradox}

When households experience fluctuations in wellbeing, repeated application of a crosssectional or static poverty measure embodies a particular set of normative judgements and discards relevant information. Several chronic and intertemporal poverty measures that may be applied to evaluate poverty over an extended period of time have been suggested in a rapidly developing literature. The various measures differ in the way that they rank alternative trajectories of wellbeing and thus embody different normative judgements about the relative undesirability of the trajectories. Several of the proposed measures and the normative judgements that they embody were reviewed in some detail by Porter \& Quinn (2013), so I shall not explore them comprehensively here, but rather focus on the issues that are most relevant to the objective of this paper.

Assume the availability of a ratio-scale indicator of wellbeing ${ }^{4} x_{i t}$ where $x_{i t} \in \mathbb{R}_{++}$, for each of $n$ individuals $(i=1,2, \ldots, n)$ in each of $T$ time periods $(t=1,2, \ldots, T)$. All individual-period wellbeings may be gathered into the $(n \times T)$ matrix $X$ while an individual's trajectory of wellbeings may be represented by the $T$-tuple $\boldsymbol{x}_{i}=\left(x_{i 1}, x_{i 2}, \ldots, x_{i T}\right)$. There is a poverty line $z$ where $z \in \mathbb{R}_{++}$.

An intertemporal or chronic poverty measure is a function $P(X, z)$, where $P: \mathbb{R}_{++}^{n T} \times$ $\mathbb{R}_{++} \rightarrow \mathbb{R}$, that aggregates wellbeing information over time and over individuals to determine an overall level of poverty. All of the measures that shall be considered are symmetric and separable over individuals, so for each there exists an 'individual' real-valued intertemporal poverty measure $p\left(\boldsymbol{x}_{i}, z\right)$ that represents the unique ordering of wellbeing trajectories embodied by that measure.

Furthermore, for all of the measures that shall be considered and for all individual wellbeing trajectories $\boldsymbol{x}_{i} \in \mathbb{R}_{++}^{T}$ there exists a constant-wellbeing equivalent ${ }^{5} \tilde{x}\left(p\left(\boldsymbol{x}_{i}, z\right)\right)=\tilde{x}_{i}$ such that $p\left(x_{i 1}, x_{i 2}, \ldots, x_{i T}, z\right)=p\left(\tilde{x}_{i}, \tilde{x}_{i}, \ldots, \tilde{x}_{i}, z\right)$. That is, a constant level of wellbeing that is evaluated to be equivalent in terms of individual poverty to the individual's actual trajectory.

There may not exist an analytical expression for $\tilde{x}\left(p\left(\boldsymbol{x}_{i}, z\right)\right)$, in which case it may be evaluated numerically. The measure proposed by Foster \& Santos (2013), defined in equation (5) below, does have a simple analytical expression $\tilde{x}\left(p_{\mathrm{FS}}\left(\boldsymbol{x}_{i}, z\right)\right)=z /(p+1)$.

The focus of this paper is on normative judgements relating to the ordering of wellbeing trajectories embodied by various intertemporal and chronic poverty measures. Different authors have taken different approaches to the aggregation over individuals, but to maintain comparability I shall, for each measure, aggregate over individuals according

\footnotetext{
${ }^{4}$ Strictly speaking, measurement units should be specified. But as the indicator will enter all of the measures only as a ratio with the poverty line, units cancel and for simplicity are not notated.

${ }^{5}$ This may be a function or a correspondence; it does not matter which.
} 
to the squared poverty gap of its constant-wellbeing equivalent

$$
P_{2}(X, z)=\frac{1}{n} \sum_{i=1}^{n}\left(\frac{z-\tilde{x}_{i}}{z}\right)^{2} .
$$

As a static poverty measure, $P_{2}$ was popularised by Foster et al. (1984) who showed that it satisfies all of the properties considered essential for a poverty measure, including monotonicity, transfer and subgroup monotonicity. It has since become standard in the applied academic literature (Foster et al. 2010). Imposing a standard aggregation over individuals means that any differences in results across different measures may be ascribed, without ambiguity, to the different orderings of wellbeing trajectories embodied by the measures.

I now focus on the properties of the trajectory ordering represented by alternative individual poverty measures $p\left(\boldsymbol{x}_{i}, z\right)$, which represent alternative normative judgements about the undesirability of different trajectories. Porter \& Quinn (2013) discuss two properties that reflect particular aversion to chronicity of poverty.

(1) Duration Sensitivity: For any poor trajectory, a transfer of wellbeing between periods such that the number of periods below the poverty line $z$ increases must increase poverty.

(2) Contiguity: When applied to two trajectories comprising the same set of wellbeings in a different sequence, the individual measure evaluates as more poor that sequence in which more of the wellbeings below the poverty line $z$ are contiguous.

Many of the measures that have been described as 'chronic' poverty measures, for example those suggested by Jalan \& Ravallion (2000), Calvo \& Dercon (2009) and Foster \& Santos (2013), are not in fact sensitive to persistence or chronicity of poverty as such, not satisfying duration sensitivity or contiguity. Other measures, suggested by Foster (2009), Gradin et al. (2011), Bossert et al. (2012) and Dutta et al. (2013) are sensitive to chronicity. For illustration I shall apply Foster's measure

$$
p_{\mathrm{F}}\left(\boldsymbol{x}_{i}, z\right)=\frac{1}{T} \sum_{t=1}^{T}\left(1-\frac{x_{i t}}{z}\right)^{\alpha} \mathbb{I}\left(x_{i t} \leq z\right) \mathbb{I}\left(\sum_{t=1}^{T} \mathbb{I}\left(x_{i t} \leq z\right) \geq \tau T\right)
$$

with $\alpha=2$ and duration-cutoff $\tau=0.6$, and Gradin et al.'s measure (closely related to Bossert et al.'s measure)

$$
p_{\mathrm{G}}\left(\boldsymbol{x}_{i}, z\right)=\frac{1}{T} \sum_{t=1}^{T}\left(1-\frac{x_{i t}}{z}\right)^{\alpha} w_{i t}
$$

where

$$
w_{i t}=\left(\frac{s_{i t}}{T}\right)^{\beta}
$$

and $s_{i t}$ is the length of the 'spell' of poverty (number of periods below $z$ ), with $\alpha=2$ and $\beta=1$.

However, these chronicity-sensitive measures have some less appealing properties. Each of those mentioned embodies an ordering of wellbeing trajectories that is discontinuous, meaning that an infinitesimal change in an individual-period wellbeing can have a substantial impact on measured poverty. Furthermore, they have the counterintuitive 
property of allowing a greater degree of compensation between periods of very deep poverty than between periods of less deep poverty.

To illustrate, consider the two-period trajectory $\left(x_{i 1}, x_{i 2}\right)=(40,20)$ where the poverty line is $z=100$; the individual is poor in every period and $p_{\mathrm{F}}=0.5$. Consider a reduction in wellbeing in the second (poorer) period, where wellbeing in the first period is increased to fully compensate, so that there is no change in the poverty measure. The first period wellbeing must be increased by $4 / 3$ units for each unit decrease in second period wellbeing.

Now consider the two-period trajectory $\left(x_{i 1}, x_{i 2}\right)=(80,40)$; the individual is still poor in every period, but less poor, and $p_{\mathrm{F}}=0.2$. Again consider a reduction in wellbeing in the second (poorer) period, accompanied by a compensating increase of wellbeing in the first period. Now the first period wellbeing must be increased by 3 units for each unit decrease in second period wellbeing.

There is a lower degree of compensation between periods of less deep poverty than between periods of profound poverty. This conflicts with the reasonable normative judgement that it should be more difficult to compensate for periods of profound poverty, and is closely related to the property of particular aversion to fluctuations in wellbeing when poverty is deeper. It may be stated more formally:

(3) Non-Decreasing Compensation: Given a poor trajectory, the marginal rate of compensation between wellbeings in a more-poor and a less-poor period should not decrease, as the period wellbeings increase in proportion.

While there is no fundamental conflict between continuity and sensitivity to chronicity of poverty, there is a conflict between sensitivity to chronicity of poverty and nondecreasing compensation. This relationship is discussed by Porter \& Quinn (2012). It is important to note that all of the poverty measures are weakly monotone and so evaluate as worse trajectories in which wellbeing is less in every period; the interesting inconsistencies arise in the way the measures evaluate trajectories that are worse in some periods but better in others.

The conflict between the apparently normatively desirable properties of sensitivity to chronicity and particular aversion to fluctuations when poverty is deeper is unsatisfactory. I suggest that the desire for a poverty measure to reflect sensitivity to chronicity is not because a trajectory that is chronically poor should be judged to be intrinsically worse than a fluctuating trajectory that reaches deeper poverty transiently, but because the poverty analyst implicitly considers persistence of poverty over several observations to predict poverty in unobserved periods, either between observations or into the future. In fact, some of the authors who introduced the chronicity-sensitive measures mentioned above explicitly made such an argument to motivate these properties.

This leads to the possibility that the normative evaluation exercise be separated from the positive modelling and prediction of unobserved wellbeings. For the latter, a dynamic model could be estimated to model explicitly the evolution of individual or household wellbeings in unobserved periods. For the former, an intertemporal poverty measure that satisfies non-decreasing compensation and is particularly sensitive to fluctuations should be applied to both the observed and modelled data. Appropriate measures include 
those suggested by Foster \& Santos (2013), an example ${ }^{6}$ being

$$
p_{\mathrm{FS}}\left(\boldsymbol{x}_{i}, z\right)=\max \left[0, \frac{1}{T} \sum_{t=1}^{T}\left(\left(\frac{x_{i t}}{z}\right)^{-1}-1\right)\right]
$$

or Porter \& Quinn (2013), an example ${ }^{7}$ being

$$
p_{\mathrm{PQ}}\left(\boldsymbol{x}_{i}, z\right)=\max \left[0, \frac{1}{3 T} \sum_{t=1}^{T}\left(\left(\frac{z}{x_{i t}}\right)^{2}+\ln \left(\frac{z}{x_{i t}}\right)-1\right)\right] .
$$

In the subsequent sections I describe the data, develop appropriate dynamic models, then apply the intertemporal poverty measures to the observed and modelled wellbeing data to evaluate poverty in rural Ethiopia over the period 1994-2004. I compare the results to those obtained by the 'chronic' poverty measures that, I argue, implicitly combine the normative and positive aspects of this analysis.

\section{The Data}

The approach proposed in this paper will be illustrated by application to data from the Ethiopian Rural Household Survey (ERHS). This is a panel or longitudinal study conducted by the International Food Policy Research Institute (IFPRI) in collaboration with the Economics Department, Addis Ababa University (Economics/AAU) and the Centre for the Study of African Economies (CSAE), University of Oxford. Households in eighteen Peasant Associations ${ }^{8}$ (PAs) in rural Ethiopia were surveyed twice in 1994, then in 1995, 1997, 1999 and 2004..$^{9}$ The eighteen Peasant Associations surveyed belong to fifteen different districts (Woredas). Within each Peasant Association surveyed, the households were randomly sampled subject to stratification into female-headed/non-female-headed and landless/non-landless categories. (Six of the PAs had been included in a 1989 IFPRI study; in these PAs the sample was re-randomised.) The sample sizes in the eighteen PAs were chosen so that proportions in the pooled sample were representative of the agro-climatic zones of Ethiopia. ${ }^{10}$

The original analysis of poverty and poverty changes in the ERHS sample was made by Dercon \& Krishnan (1998) who analysed data from the first three rounds, comparing with data from the 1989 IFPRI survey for those households included in both surveys. Dercon \& Krishnan constructed a household aggregate consumption measure comprising the nominal value of purchased and non-purchased food items consumed as well as non-investment non-food items, but excluding expenditure on durables, house expenses,

\footnotetext{
${ }^{6}$ This is Foster \& Santos's measure of chronic poverty with parameter $\beta=-1$, in which trajectories of wellbeings are ordered by their harmonic mean, reflecting a fairly low elasticity of intertemporal compensation or high aversion to fluctuations.

${ }^{7}$ This is Porter \& Quinn's measure of intertemporal poverty with parameter $k=2$, reflecting a lower elasticity of intertemporal compensation than $p_{\mathrm{FS}}$; the elasticity of intertemporal compensation increases as the depth of poverty lessens.

${ }^{8}$ Created after the 1974 revolution, Peasant Associations are the lowest level administrative division in rural Ethiopia. Each comprises one or a few villages.

${ }^{9} \mathrm{~A}$ seventh round has been collected more recently but at the time of writing comparable aggregates are not available.

${ }^{10}$ Detailed sampling documentation may be found at www.csae.ox.ac.uk/datasets/EthiopiaERHS/erhs/docoutline-erhs.html.
} 
health and education. This was scaled according to the household composition to give a per-adult-equivalent monthly value, following World Health Organisation guidelines for weighting male and female adults and children.

Dercon \& Krishnan conducted their poverty analysis of the consumption aggregate relative to a poverty line determined by the cost-of-basic-needs approach; a food consumption basket typical of the diet of the nominally poorest half of the sample was constructed and scaled so as to provide 2300 Calories (kilocalories) per day. The non-food share of consumption for a household at the poverty line was estimated and the nominal value of the poverty line was computed for each PA in each period, using local prices. More details and a comprehensive discussion of the issues arising may be found in Dercon \& Krishnan (1998). Porter (2008) extended the analysis to include the later rounds of the ERHS, omitting round 2 (the second 1994 round) to avoid seasonality issues (the first three rounds had been conducted in a very short time frame in comparison to the rest of the survey).

\subsection{Wellbeing Indicator}

The EHRS data includes comprehensive information on household income and consumption as well as household and individual characteristics. Porter (2008) and Porter \& Quinn (2013) use the monthly consumption aggregate as constructed by Dercon \& Krishnan (1998) and extended by Porter (2008) as an indicator of wellbeing for the analysis of poverty. This is partly because it is well-established that consumption data is more reliable than income data in the ERHS and similar household surveys, but primarily because value of consumption already takes into account the household's intertemporal smoothing strategies and thus serves as a much better proxy for experienced wellbeing. The same consumption aggregate is used for the analysis in this paper.

In order to establish comparability between households (within PA) and over time, the consumption aggregate has been deflated to 1994 prices for each locality, and by the number of adult equivalents present in the household in each period. The real, per-adult-equivalent consumption aggregate for household $i$ in PA $j$ in time period $t$ is $x_{i j t}$. The unit-period wellbeing indicators enter into all of the poverty measures that are considered only as a proportion of the poverty line (that is, as $\frac{x}{z}$ ) so comparability between PAs may be established by additionally deflating by the 1994 poverty line in local prices $z_{j t}$ calculated by Dercon \& Krishnan (1998). The resulting consumption ratio $\frac{x_{i j t}}{z_{j t}}$ is comparable between households (within PA), between PAs and over time. The consumption ratio is greater than one for a household above the poverty line and below one for a household below the poverty line. Its natural logarithm, denoted $r_{i j t}=$ $\ln \left(x_{i j t}\right)-\ln \left(z_{j t}\right)$, is positive for a household above the poverty line and negative for a household below the poverty line.

\subsection{Unit of Analysis}

The consumption data in the EHRS is measured at household rather than individual level. In order to estimate the population incidence of poverty (although not allowing for intrahousehold distribution issues) it would be necessary to weight by household size when aggregating over the sample. As this paper is primarily methodological and a test of concept, I take the household as the unit of analysis and so do not perform this weighting. Care must therefore be taken to interpret the results as estimates for the population of 
households and not for the population of individuals.

\subsection{Sub-sample}

A total of 1477 households were sampled in the first round of the ERHS; attrition was relatively low. Following Porter (2008) I use data from rounds 1, 3, 4, 5 and 6 only, restricting analysis to the 1218 households for which the consumption aggregate is available in at least three of these five rounds. The temporal patterns of consumption aggregate availability for these households are recorded in Table 1; for each of the rounds used (in order) 1 indicates that the consumption aggregate is available while 0 indicates that it is not available.

Table 1: Temporal patterns of consumption aggregate a
\begin{tabular}{|l|rrr|}
\hline Pattern & Frequency & Percent & Cumulative \\
\hline 11111 & 1089 & 89.41 & 89.41 \\
11110 & 93 & 7.64 & 97.04 \\
10111 & 25 & 2.05 & 99.10 \\
10110 & 5 & 0.41 & 99.51 \\
01111 & 2 & 0.16 & 99.67 \\
01110 & 1 & 0.08 & 99.75 \\
10011 & 1 & 0.08 & 99.84 \\
11011 & 1 & 0.08 & 99.92 \\
11101 & 1 & 0.08 & 100.00 \\
\hline Total & 1218 & 100.00 \\
\hline \multicolumn{4}{|c}{ Source: ERHS, rounds $1,3,4,5$ and 6} \\
\hline
\end{tabular}

As non-availability of the data is likely to be correlated with household characteristics and wellbeing, it should be noted that there is the potential for selection bias if the results are interpreted as estimates of poverty incidence in the sampled villages or in rural Ethiopia as a whole.

\subsection{Descriptive Statistics By Round}

The consumption ratio is summarized in Table 2 across the sub-sample, by PA. It may be seen that in most PAs there is a general trend of increasing wellbeing over the period covered by the study (1994-2004); several PAs have a significant upward trend while Adele is the only to have a significant downward trend. This pattern is reflected in the PA poverty headcounts summarised in Table 3, which increase over the period, most PAs having a substantial downward trend with Adele being the only PA to have a substantial upward trend.

Pooling across the whole sub-sample (1218 households, five rounds), Table 4 records summary statistics for the consumption ratio and its natural logarithm.

While the Shapiro-Francia test rejects normality of both variables (with p-values of 0.00034 and 0.04303 respectively) it does so less strongly for the logarithm of the consumption ratio. The empirical cumulative distribution function (CDF) of the consumption ratio (Figure 1) is clearly non-normal while the empirical CDF of its natural logarithm (Figure 2) is reasonably closely approximated by a normal distribution. This is consistent with consumption being determined by a process of multiplicative shocks and indicates 
Table 2: Mean consumption ratio, by Peasant Association

\begin{tabular}{|l|r|r|rrrrr|}
\hline PA & \# HH & Pov line & ratio94 & ratio95 & ratio97 & ratio99 & ratio04 \\
\hline Haresaw & 74 & 44.00 & 1.77 & 1.87 & 2.64 & 2.39 & 1.92 \\
Geblen & 58 & 55.00 & 0.69 & 0.75 & 1.90 & 1.37 & 2.23 \\
Dinki & 76 & 44.00 & 1.46 & 1.20 & 1.49 & 2.01 & 2.04 \\
Yetemen & 53 & 40.00 & 3.36 & 1.86 & 2.85 & 2.16 & 3.17 \\
Shumsheha & 109 & 42.00 & 3.07 & 3.09 & 2.89 & 3.59 & 3.44 \\
Sirbana Godeti & 72 & 38.00 & 3.11 & 2.88 & 2.97 & 4.93 & 5.53 \\
Adele & 86 & 53.00 & 2.12 & 2.68 & 2.84 & 1.72 & 1.58 \\
Korodegaga & 88 & 44.00 & 0.92 & 1.18 & 1.65 & 2.40 & 1.74 \\
Trurufe Ketchema & 88 & 36.00 & 2.95 & 2.04 & 2.39 & 3.81 & 3.62 \\
Imdibir & 62 & 38.00 & 1.31 & 0.93 & 1.85 & 1.51 & 1.47 \\
Aze Deboa & 56 & 36.00 & 2.75 & 1.85 & 2.50 & 1.04 & 3.15 \\
Adado & 82 & 41.00 & 2.04 & 1.46 & 2.60 & 1.92 & 1.36 \\
Gara Godo & 91 & 49.00 & 0.61 & 0.59 & 1.15 & 1.14 & 1.91 \\
Domaa & 56 & 58.00 & 0.85 & 1.82 & 1.14 & 1.83 & 1.82 \\
db-Milki & 57 & 49.00 & 2.35 & 1.96 & 4.59 & 3.06 & 4.06 \\
db-Kormargefia & 53 & 49.00 & 2.09 & 1.84 & 3.60 & 3.12 & 3.53 \\
db-Karafino & 33 & 49.00 & 2.48 & 1.43 & 2.74 & 2.84 & 2.68 \\
db-Faji Bokafia & 24 & 49.00 & 2.51 & 1.87 & 3.63 & 3.44 & 5.22 \\
\hline Total/Mean & 1215 & 44.70 & 2.00 & 1.78 & 2.43 & 2.46 & 2.66 \\
\hline
\end{tabular}

Number of households, poverty line in Ethiopian birr per month per adult equivalent (1994 prices) and consumption ratio for each round. Source: ERHS, rounds 1, 3, 4, 5 and 6, own calculations.

Table 3: Poverty headcount by PA

\begin{tabular}{|l|rrrrr|}
\hline PA & $\mathbf{1 9 9 4}$ & $\mathbf{1 9 9 5}$ & $\mathbf{1 9 9 7}$ & $\mathbf{1 9 9 9}$ & $\mathbf{2 0 0 4}$ \\
\hline Haresaw & 0.27 & 0.41 & 0.19 & 0.14 & 0.25 \\
Geblen & 0.84 & 0.81 & 0.31 & 0.52 & 0.27 \\
Dinki & 0.49 & 0.49 & 0.41 & 0.29 & 0.19 \\
Yetemen & 0.04 & 0.17 & 0.06 & 0.19 & 0.04 \\
Shumsheha & 0.08 & 0.05 & 0.08 & 0.01 & 0.01 \\
Adele & 0.10 & 0.01 & 0.04 & 0.00 & 0.00 \\
Korodegaga & 0.15 & 0.07 & 0.05 & 0.35 & 0.33 \\
Trurufe Ketchema & 0.65 & 0.53 & 0.26 & 0.14 & 0.28 \\
Imdibir & 0.13 & 0.17 & 0.15 & 0.09 & 0.10 \\
Aze Deboa & 0.34 & 0.76 & 0.24 & 0.37 & 0.43 \\
Adado & 0.14 & 0.52 & 0.23 & 0.59 & 0.14 \\
Gara Godo & 0.22 & 0.41 & 0.17 & 0.24 & 0.40 \\
Domaa & 0.87 & 0.84 & 0.63 & 0.57 & 0.37 \\
db-Milki & 0.77 & 0.36 & 0.55 & 0.29 & 0.30 \\
db-Kormargefia & 0.26 & 0.33 & 0.05 & 0.04 & 0.02 \\
db-Karafino & 0.25 & 0.23 & 0.04 & 0.11 & 0.02 \\
db-Faji Bokafia & 0.24 & 0.24 & 0.06 & 0.09 & 0.09 \\
Mean & 0.21 & 0.25 & 0.00 & 0.13 & 0.00 \\
& 0.34 & 0.37 & 0.21 & 0.23 & 0.20 \\
\hline
\end{tabular}

Source: ERHS, rounds 1, 3, 4, 5 and 6, own calculations. 
Table 4: Summary statistics for consumption ratio and its logarithm

\begin{tabular}{|l|rrrrr|}
\hline Variable & Obs & Mean & Std. Dev & Min & Max \\
\hline Consumption ratio & 5954 & 2.261391 & 2.324249 & 0.029614 & 59.99699 \\
Log cons ratio & 5954 & 0.478647 & 0.829217 & -3.519497 & 4.09430 \\
\hline
\end{tabular}

that the usual convention using the logarithm of consumption as the dependent variable in linear models, which I shall follow in section 4, is appropriate.

Figure 1: Consumption ratio: Empirical CDF and fitted normal

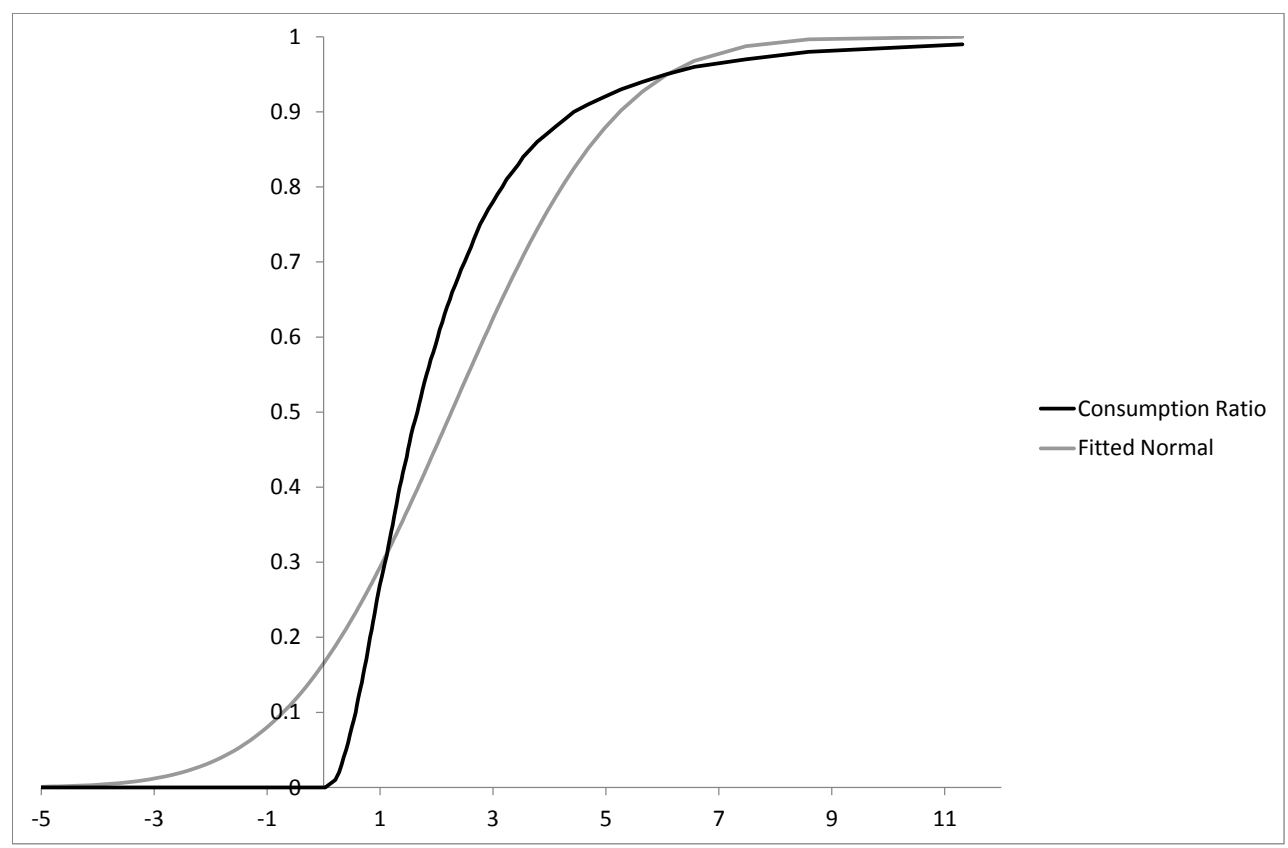

\section{Dynamic Models}

In this section I describe four approaches that may be used to model explicitly the evolution of the household wellbeing indicator over time.

As discussed above, chronic poverty measures may be thought of as implicitly taking account of wellbeing in the future (beyond the period for which data is available) and wellbeing in time-periods between observations. If the poverty analyst is interested in lifetime wellbeing then it is necessary to model both. However, future wellbeing has significant challenges associated with lifetime duration; how to model, and how to evaluate length of life normatively in the poverty measure. While these difficulties will not be insurmountable, for now I focus on wellbeing in time-periods between observations.

The irregular time-structure of the ERHS provides an ideal environment in which to develop methods. As the consumption ratio discussed above will be used as the indicator of wellbeing for poverty measurement, it is that variable that must be predicted when unobserved. While the consumption ratio refers to consumption per month (constructed 
Figure 2: Log consumption ratio: Empirical CDF and fitted normal

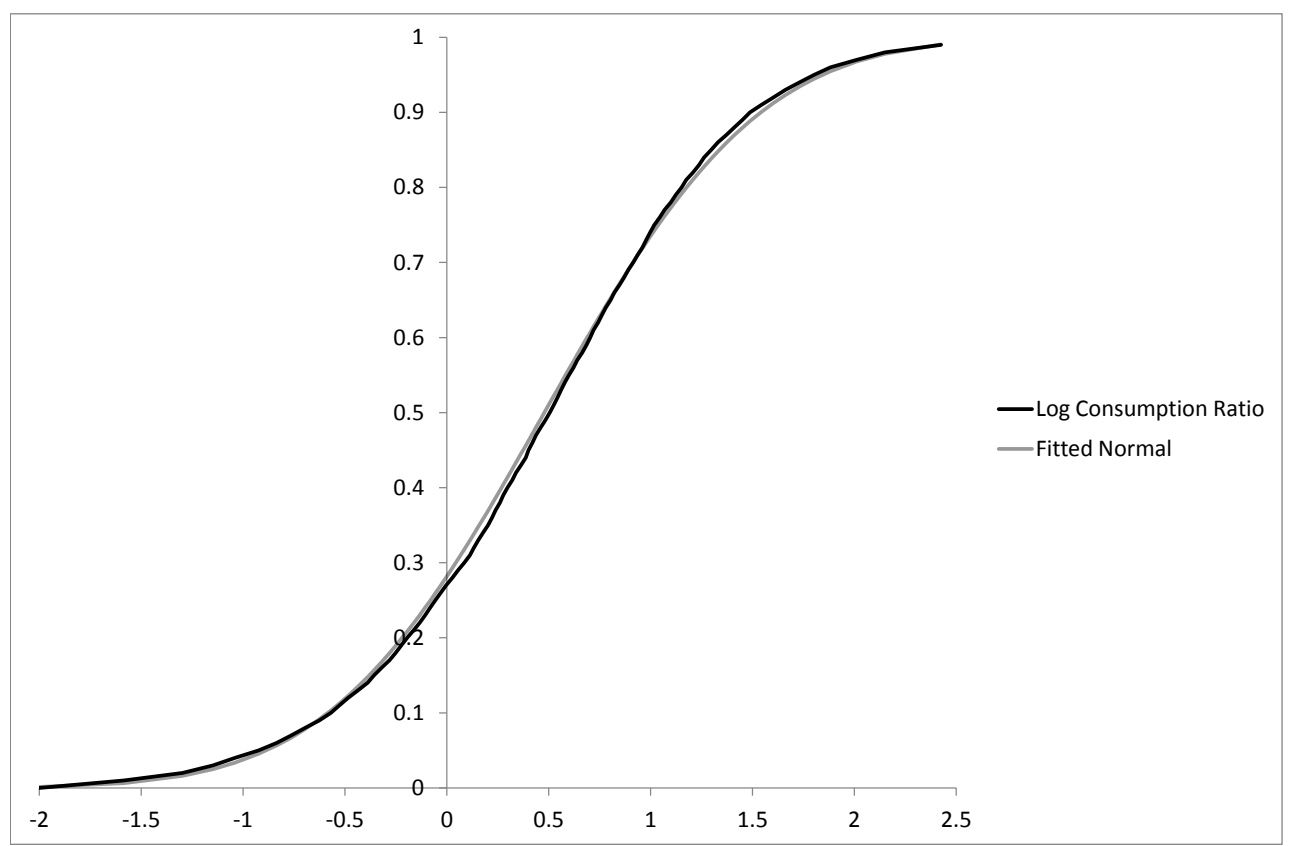

from recall questions covering a variety of periods) I treat it as an indicator of wellbeing in the year of observation; it is therefore necessary to predict it in the intervening years between rounds of the survey, that is, 1996, 1998, 2000, 2001, 2002 and 2003. Its logarithm approximates a normal distribution more closely than the consumption ratio itself and so is used as the dependent variable throughout this section; this is beneficial in order to minimise specification errors and for the sample properties of the estimators.

The application of statistical and econometric methods to model evolution of wellbeing over time at individual or household level is not new; beyond the descriptive analyses of poverty dynamics that have been carried out in many contexts, work led by Dercon (2004a, 2006) and continued by Dercon et al. (2009) and Porter (2010) among others has elucidated the causal impact of factors (policy, shocks and characteristics) on household or individual wellbeing.

The empirical methods suggested here differ significantly from the methods applied in the studies mentioned above. Those studies focussed on elucidating causal impacts of various factors and their authors therefore paid close attention to identification and avoidance of bias in the parameter estimates. In the present analysis I am not concerned with causal interpretation but with effective prediction, on the basis of the observed trajectory of wellbeing levels, and may therefore make use of simpler empirical strategies to model wellbeing dynamics. Furthermore, this approach more closely reflects the implicit modelling exercise that may motivate adoption of a measure that is particularly sensitive to chronicity of poverty.

In fact, there are limits in the extent to which household characteristics may be used to predict wellbeing. Time-invariant household characteristics are taken into account through household-specific intercepts and slopes (depending on the model) and so need not explicitly enter the models. It is more difficult to deal with time-varying charac- 
teristics. While any such characteristic that has explanatory power for wellbeing would improve the accuracy of the model, the reason for constructing the model is to predict wellbeing in periods in which data is not available and so the inclusion of the instantaneous effect of such characteristics cannot add anything and in fact would render the model ineffective for prediction. It may be possible to account for dynamic effects; construction of such a model would not be straightforward when the time-structure of the data is not regular, as in the ERHS.

\subsection{Model A: Linear Interpolation}

The most straightforward approach is to interpolate wellbeings between observations. Linear interpolation of the logarithm of the consumption ratio corresponds to an assumption of constant growth rate of consumption between observations. This is not unreasonable but might tend to underestimate variability in wellbeing over time, which will lead to a downward bias in any poverty measure that is sensitive to variability over time. An attractive characteristic of this method is that it is not necessary to impose any homogeneity assumptions across households; the interpolation may be carried out separately for each household.

Consider time periods $s$ and $f$ in which wellbeing is observed, with no observations in between. If household $i$ 's log consumption ratio is $r_{i s}$ in the earlier observation period and $r_{i f}$ in the later, then the interpolated value in period $t$ between $s$ and $f$ is

$$
r_{i t}=\frac{r_{i f}-r_{i s}}{f-s}(t-s)+r_{i s}
$$

The irregular time structure of the dataset does not pose any particular challenges for this method.

The interpolation was carried out separately for each household; Figure 3 illustrates for one particular household. (This household was chosen semi-arbitrarily; its trajectory of observed consumption ratios demonstrates the general trend of increase over time with significant variability around the trend.) As the poverty measures are functions of the consumption ratio, the modelled values must be de-logged before the poverty measures are calculated. The de-logged predicted consumption ratios are illustrated, for the same household, in Figure 4. 
Figure 3: Log consumption ratio predictions (Model A)

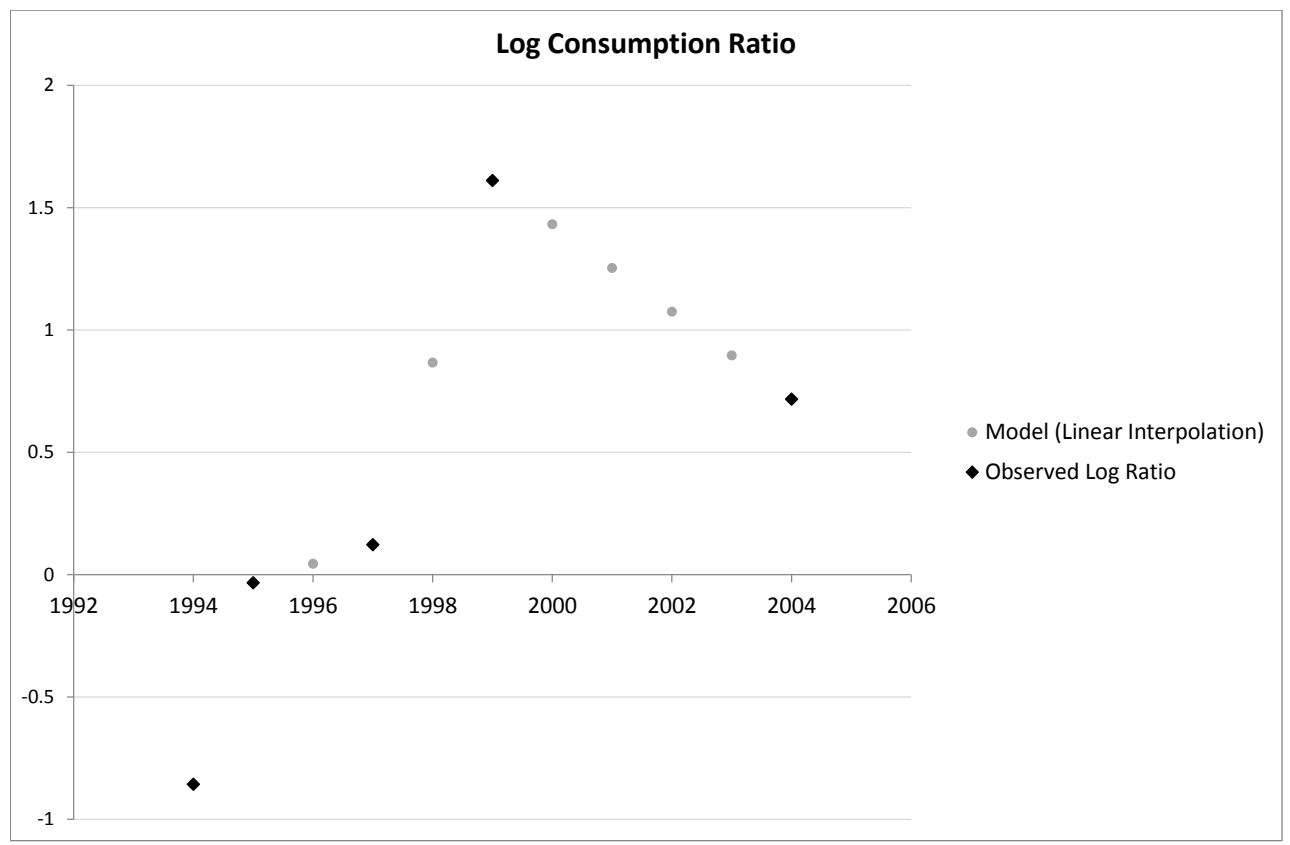

Figure 4: Consumption ratio predictions (Model A)

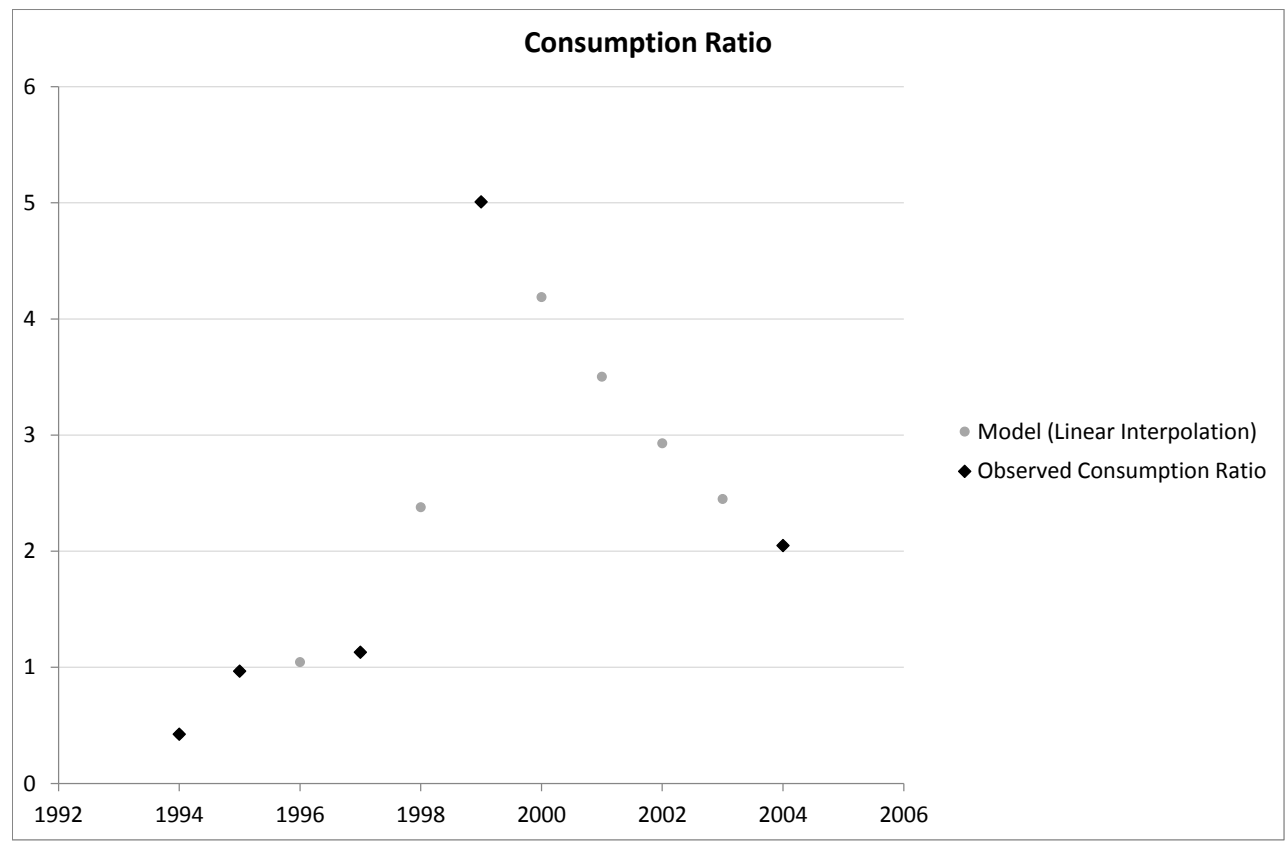




\subsection{Model B: Household-Specific Time Trends}

The next approach is to model the log consumption ratio in unobserved periods according to its linear trend over the observed periods. (This corresponds to an assumption of constant growth rate of the consumption ratio over time.) There is considerable variation in the experiences of households in the sample, many exhibiting a trend of increasing wellbeing over time while others suffer a decline. With five observations per household, there is sufficient data to determine the trend experienced by each household individually. Again, it is not necessary to make any assumption of homogeneity across households.

The model for log consumption ratio experienced by household $i$ in period $t$

$$
r_{i t}=\alpha_{i}+\beta_{i} t+u_{i t}
$$

may then be estimated for each household (OLS was used) and the estimates used to predict the log consumption ratio in unobserved periods,

$$
\hat{r}_{i t}=\hat{\alpha}_{i}+\hat{\beta}_{i} t
$$

$\hat{\alpha}_{i}$ is the household-specific intercept and $\hat{\beta}_{i}$ the household-specific slope coefficient. In practice for computational efficiency these household-specific equations were estimated by Woreda, using the household IDs and their interations with time as the regressors.

Space precludes reporting of the household-specific slope coefficients, but they are distributed with mean 0.0439 (corresponding to an annual growth rate of consumption ratio of $4.49 \%$ on average across households) and standard deviation of 0.0853 .

It is clear that this approach will underestimate the variability of wellbeing over time, leading to a downward bias in any poverty measure which is sensitive to variability over time. This was addressed by adding a random term, so that

$$
\hat{r}_{i t}=\hat{\alpha}_{i}+\hat{\beta}_{i} t+z_{i t} \hat{\sigma}_{i}
$$

where $z_{i t}$ is a standard normal random variable and $\hat{\sigma}_{i}$ is the estimated standard deviation of the household's residuals, that is, the deviations of observed values from the regression line.

Introducing variability in this way assumes that there is no autocorrelation of shocks. If there were some degree of autocorrelation then the temporal variability of the modelled wellbeings will have been overestimated which will lead to an upward bias in any poverty measure that is sensitive to variation over time.

I believe that the degree of upward bias will be less than the degree of downward bias that would arise when the extra variation is not modelled. Although this cannot be directly ascertained, we shall assess the robustness of the results by computing the poverty measures with and without the modelled variation to determine an upper and lower bound.

Figure 5 illustrates the predicted log consumption ratio with and without the added variation, for the same household illustrated above; observed values are used in periods in which they are available. As the poverty measures are functions of the consumption ratio the predicted values must be de-logged before the poverty measures are calculated, illustrated in Figure 6. 
Figure 5: Log consumption ratio predictions (Model B)

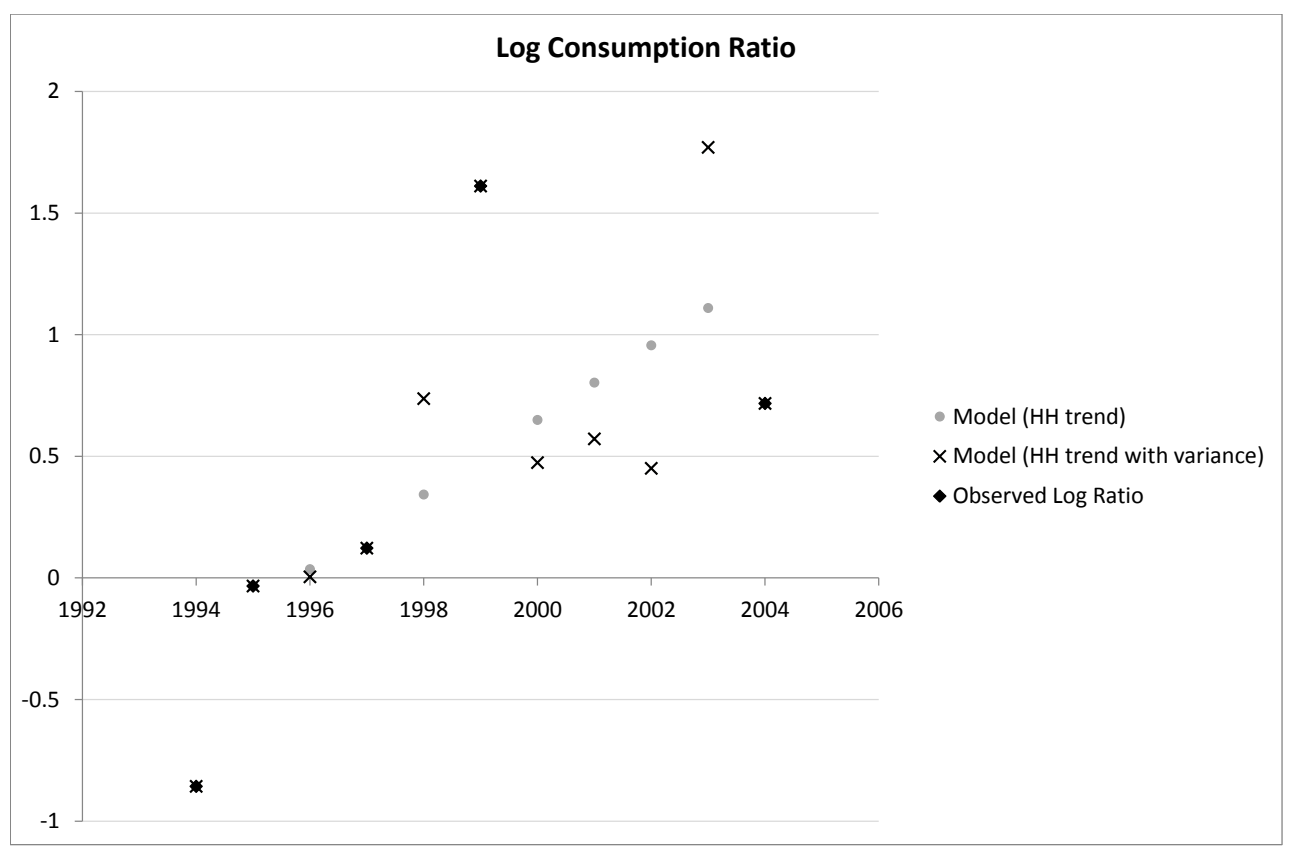

Figure 6: Consumption ratio predictions (Model B)

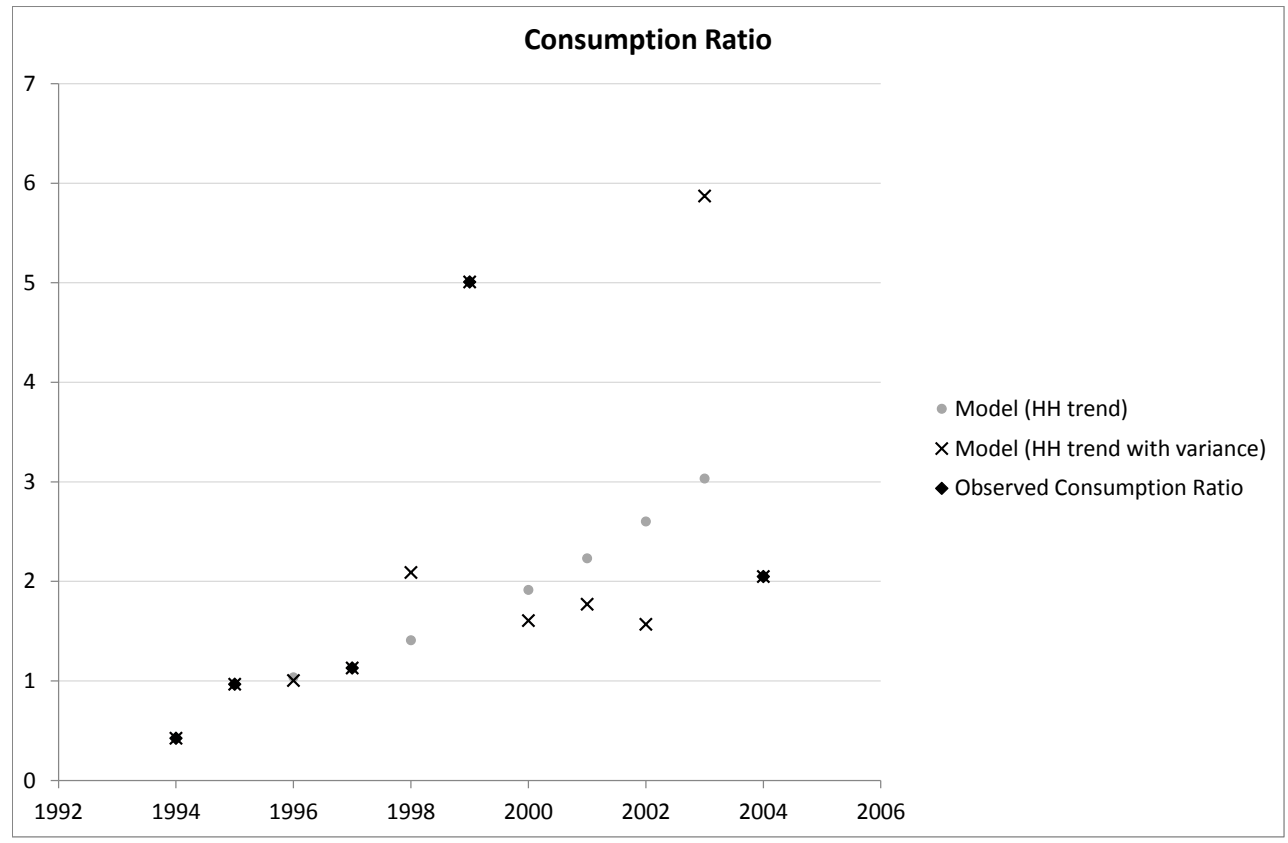




\subsection{Model C: Autoregression with Household Fixed Effect}

It may be that the evolution of household wellbeing over time is better modelled with a more sophisticated dynamic model than simple constant growth of the consumption ratio as above. In particular, it is reasonable to expect some degree of autocorrelation of wellbeing due both to autocorrelation of shocks and persistence of their effect. A first-order autoregressive model is perhaps the most straightforward way to incorporate autocorrelation in the model.

Unfortunately, the irregular time structure of the dataset means that it is not possible to use all rounds to estimate the model, but the evenly-spaced observations from 1995, 1997 and 1999 may be used. There is not enough data to estimate household-specific autocorrelation but it is possible to include household fixed effects to account for the variation in level of wellbeing between households. The model to be estimated is thus

$$
r_{i t}=\alpha_{i}+\beta r_{i(t-2)}+u_{i t}
$$

1216 households were included in the estimation sample (all those for which observations were available in 1995 and 1997 and/or 1997 and 1999) and the value of the estimated autoregressive coefficient was $\hat{\beta}=-0.412$ (standard error 0.025 ). The household-specific constants are too numerous to report. The magnitude of the autoregressive coefficient is significantly different from zero and from one so we can be confident that there is significant autocorrelation and that the process is stable rather than explosive. The negative coefficient demonstrates a tendency for fluctuation in the process. However, these results should be treated with caution due to the very small number of time periods. In a refined version of the model it may be possible to make use of the discarded observations from round 1 and round 6 as well as other information which has been discarded.

The estimated model was used to predict the value of the log consumption ratio in the unobserved periods; several iterations were necessary to obtain predictions for all unobserved periods. The iterations utilised for each period (the lowest possible) are recorded in Table 5.

Table 5: Model iteration utilised for each year's predictions

\begin{tabular}{|c|ccccc|}
\hline Year & Observed & Iteration 1 & Iteration 2 & Iteration 3 & Iteration 4 \\
\hline 1994 & $\checkmark$ & & & & \\
\hline 1995 & $\checkmark$ & & & & \\
\hline 1996 & & $\checkmark$ & & & \\
\hline 1997 & $\checkmark$ & & & & \\
\hline 1998 & & & $\checkmark$ & & \\
\hline 1999 & $\checkmark$ & & & & \\
\hline 2000 & & & & $\checkmark$ & \\
\hline 2001 & & $\checkmark$ & & & \\
\hline 2002 & & & & & \\
\hline 2003 & & & $\checkmark$ & & \\
\hline 2004 & $\checkmark$ & & & & \\
\hline
\end{tabular}

As illustrated in Figures 7 and 8, because the estimated autoregressive process is stable, this model will tend to underestimate variation in the later time periods. To 
address this I add a random term $z_{i t} \hat{\sigma}_{i}$ to the predicted value where $z_{i t}$ is a standard normal random variable and $\hat{\sigma}_{i}$ is the estimated standard deviation of the residuals for household $i$. Figure 7 illustrates the modelled values of the log consumption ratio for one household. Figure 8 illustrates the modelled values of the consumption ratio itself.

Figure 7: Log consumption ratio predictions (Model C)

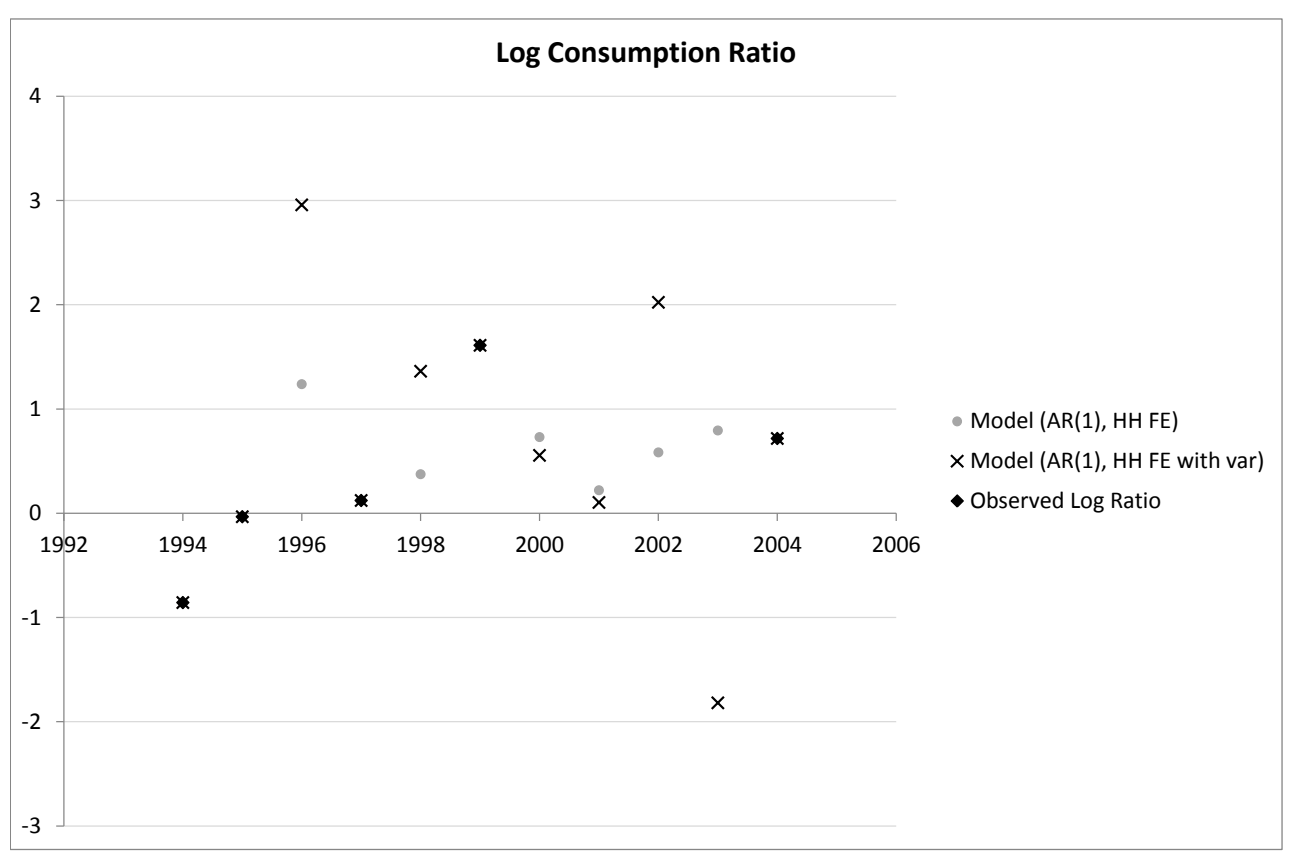


Figure 8: Consumption ratio predictions (Model C)

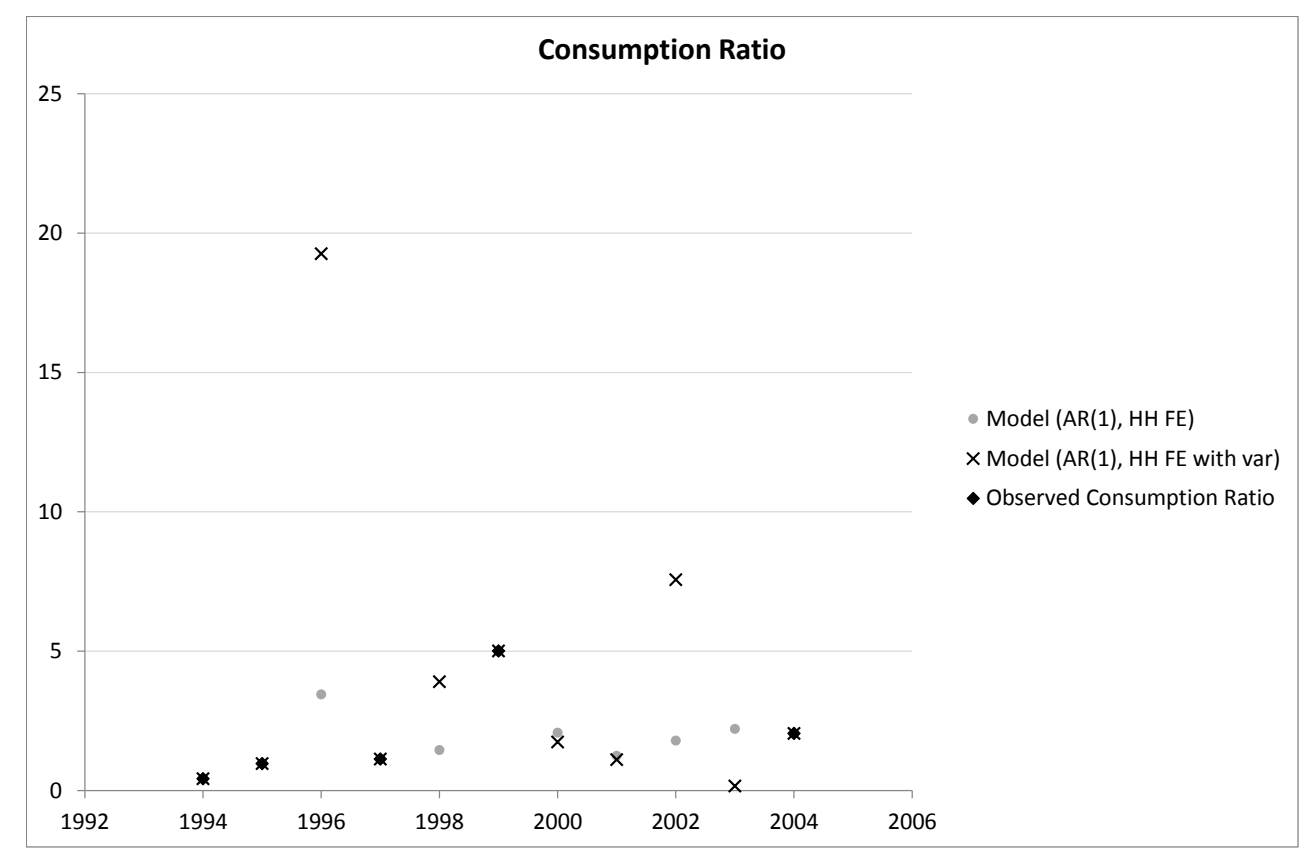

\subsection{Model D: Autoregression with PA Trend and Household Fixed Effect}

There are several limitations to the model above. One important limitation is that the stable autoregressive process tends toward a constant for each household, which cannot reflect the general upward trend in the data. As the autoregressive process can only be estimated from three rounds due to the irregular time structure, it is impossible to incorporate household-specific trend terms as well as constants. Different PAs experience different general trends over the survey period as illustrated in section 3 so a trend term was added at this level. The model is thus, for household $i$ in PA $j$ in time period $t$,

$$
r_{i j t}=\alpha_{i j}+\beta r_{i j(t-2)}+\gamma_{j} t+u_{i j t} .
$$

The estimated autoregressive and trend coefficients are given in Table 6 .

There is a significant upward trend for many of the PAs but a significant downward trend for Adele and Aze Deboa. The highly significant negative autoregressive coefficient again indicates a stable fluctuating process. As above we may add a random term to introduce variability to the modelled values. Figure 9 illustrates the modelled values of the log consumption ratio for one household. Figure 10 illustrates the modelled values of the consumption ratio itself.

\subsection{Comparison and Evaluation of the Dynamic Models}

The assumptions and limitations of the various methods are discussed above; none is without limitations. We may compare their efficacy by using the models to predict a value of the log consumption ratio for the year 2004 and comparing that prediction with 
Table 6: Estimated Coefficients (AR(1) with PA trends and HH FE)

\begin{tabular}{|l|rr|}
\hline Coefficient & Value & t-stat \\
\hline$\beta$ & -0.4561108 & -16.86 \\
\hline$\gamma$-Haresaw & 0.0953734 & 2.14 \\
$\gamma$-Geblen & 0.0260654 & 0.52 \\
$\gamma$-Dinki & 0.1209254 & 2.80 \\
$\gamma$-Yetemen & -0.0682304 & -1.32 \\
$\gamma$-Shumsheha & 0.1003553 & 2.77 \\
$\gamma$-Sirbana Godeti & 0.2723750 & 6.19 \\
$\gamma$-Adele & -0.2466011 & -6.01 \\
$\gamma$-Korodegaga & 0.2115403 & 5.28 \\
$\gamma$-Trurufe Ketchema & 0.2397709 & 5.78 \\
$\gamma$-Imdibir & 0.1106095 & 2.29 \\
$\gamma$-Aze Deboa & -0.2726735 & -5.40 \\
$\gamma$-Adado & -0.0100366 & -0.24 \\
$\gamma$-Gara Godo & 0.1768173 & 4.36 \\
$\gamma$-Domaa & 0.1259496 & 2.48 \\
$\gamma$-db-Milki & 0.0786189 & 1.57 \\
$\gamma$-db-Kormargefia & 0.0857802 & 1.65 \\
$\gamma$-db-Karafino & 0.1292568 & 1.96 \\
$\gamma$-db-Faji Bokafia & 0.0955113 & 1.25 \\
\hline
\end{tabular}

Source: ERHS, rounds 3, 4 and 5 .

Figure 9: Log consumption ratio predictions (Model D)

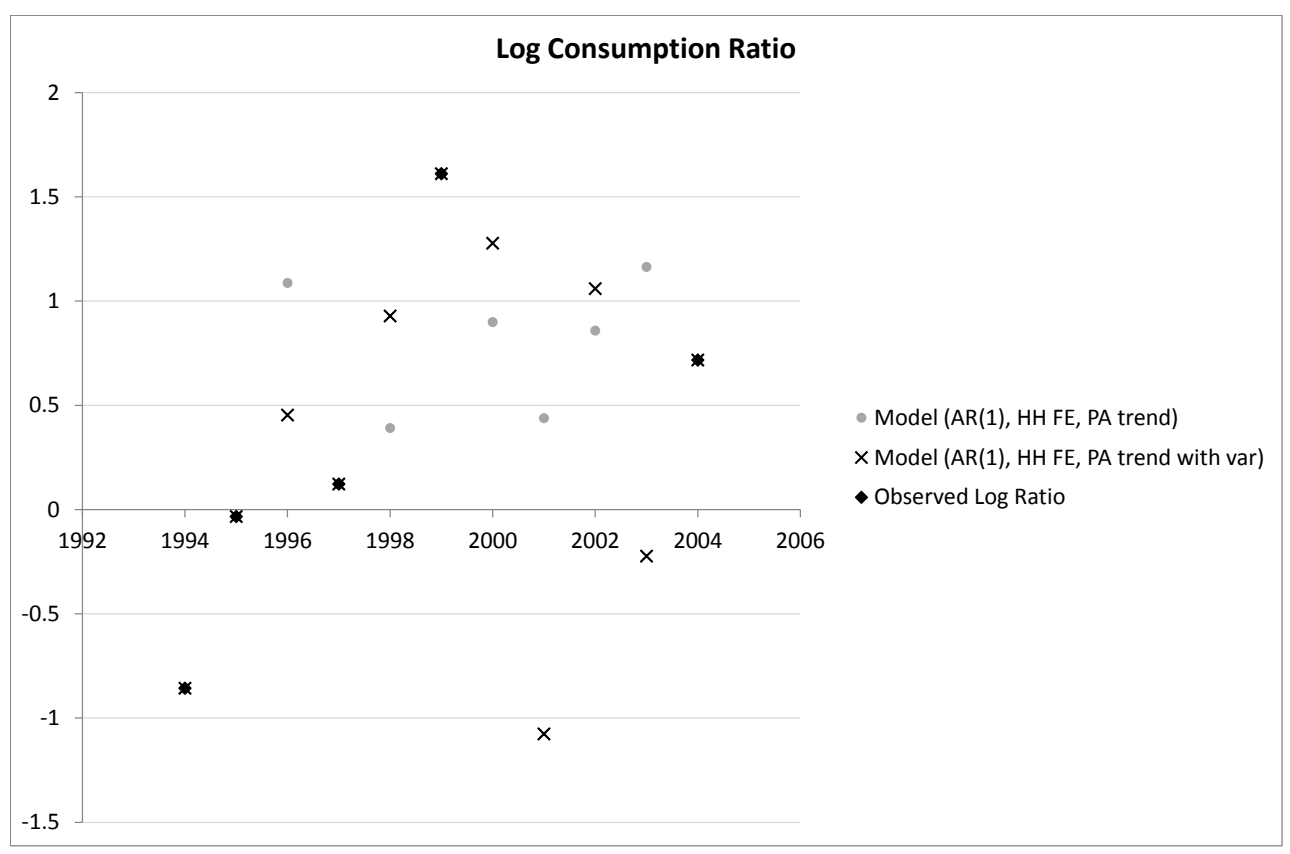


Figure 10: Consumption ratio predictions (Model D)

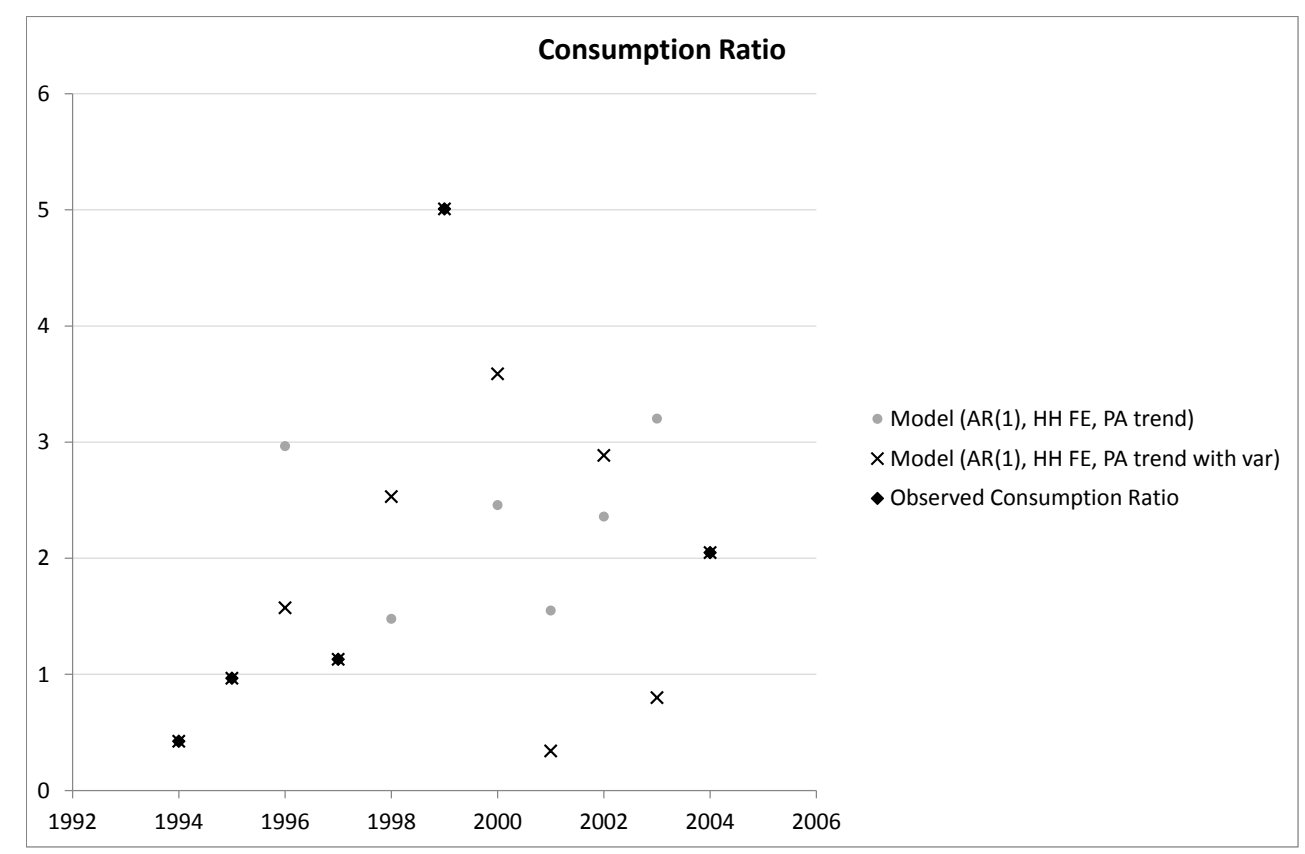

the actual value for that year, a pseudo out of sample forecasting approach. (It does not make sense to do this for the interpolation model.) Observations and predictions for 2004 are summarised in Table 7.

Table 7: Pseudo out of sample forecasts for log consumption ratio in 2004

\begin{tabular}{|l|rrrrr|}
\hline Model & N & Mean & Std. Dev. & Min & Max \\
\hline Observed & 1119 & 0.64896 & 0.79720 & -2.6171 & 3.7737 \\
B: HH-specific trends & 1119 & 0.70964 & 0.73813 & -2.1196 & 3.4622 \\
B: HH-specific trend + var & 1119 & 0.72200 & 0.88451 & -2.0418 & 4.2242 \\
C: AR(1) + HH FE & 1115 & 0.54294 & 0.60530 & -1.7055 & 2.2518 \\
C: AR(1) + HH FE + var & 1115 & 0.55272 & 0.82762 & -3.1667 & 3.5962 \\
D: AR $(1)+$ PA tt + HH FE & 1115 & 0.87844 & 0.90240 & -2.1475 & 3.4216 \\
D: AR $(1)+$ PA tt + HH FE + var & 1115 & 0.86587 & 1.02607 & -2.8153 & 4.1459 \\
\hline
\end{tabular}

The HH-specific trend models tend to overestimate the log consumption ratio in 2004 while the autoregressive plus fixed effects models tend to underestimate it; the autoregressive models with PA-specific trend tend to overestimate. The HH-specific trend models most closely model the observed values. The values predicted by the models with added variance are more widely distributed than the observed values while the values predicted by the models without added variance are more narrowly distributed, except in the case of the autoregressive model with trend.

Table 8 reports correlations between the observed and predicted values, for those households (1115) with predictions available for all models.

It is clear from these results that model B (household-specific trends) performs best 
Table 8: Correlations between forecast and actual log consumption ratios in 2004

\begin{tabular}{|l|rrrrrrr|}
\hline & Observed & B & Bvar & C & Cvar & D & Dvar \\
\hline Observed & 1.0000 & & & & & & \\
Model B & 0.9364 & 1.0000 & & & & & \\
Model Bvar & 0.7504 & 0.8064 & 1.0000 & & & & \\
Model C & 0.3637 & 0.5146 & 0.4022 & 1.0000 & & & \\
Model Cvar & 0.2457 & 0.3731 & 0.2972 & 0.7371 & 1.0000 & & \\
Model D & 0.3254 & 0.4949 & 0.4096 & 0.6825 & 0.5343 & 1.0000 & \\
Model Dvar & 0.2744 & 0.4184 & 0.3342 & 0.6011 & 0.4733 & 0.8782 & 1.0000 \\
\hline
\end{tabular}

as a predictor of the 2004 wellbeings. The relatively poor performance of models $\mathrm{C}$ and $\mathrm{D}$ is likely to be due to the fact that these models assumed a much greater degree of homogeneity across households and also discarded the information from rounds 1 and 6 .

None of the approaches implemented above is fully satisfactory from an empirical perspective. It is frustrating to discard information on time-varying household characteristics, while in the autoregressive models the irregular time structure meant that wellbeing information from rounds 1 and 6 was not incorporated. It may be possible in further work to estimate a more sophisticated model that makes use of all the wellbeing information. Furthermore, it may be possible to make use of time-varying household characteristics such as shocks and asset stocks, having carefully modelled their impact on the evolution of wellbeing ${ }^{11}$ and therefore being able to make predictions for periods in which data on the characteristics is not available. However, the exercise that was carried out - predicting the evolution of households' wellbeing levels on the basis of partially observed trajectories - does, I would argue, reflect the implicit modelling that has motivated the normative judgements embodied by the 'chronic' poverty measures discussed in section 2 .

\section{Application to Poverty Measures}

To complete the analysis, I shall combine the positive predictions of unobserved wellbeings generated by the dynamic models discussed in section 4 with the normative evaluation of poverty embodied by the chronic and intertemporal poverty measures discussed in section 2. For clarity I shall restrict analysis to the subsample of 1089 households for which consumption data is available in all five observed years (and for which the dynamic models generate predictions for all six unobserved years).

For comparison, I start with a naïve application of the aggregate chronic and intertemporal poverty measures $P_{\mathrm{F}}, P_{\mathrm{G}}, P_{\mathrm{FS}}$ and $P_{\mathrm{PQ}}$ defined in section 2 to the ERHS data, taking as time periods $t=1,2,3,4$ and 5 rounds $1,3,4,5$ and 6 of the survey without considering the irregular time structure. Applying these measures to the sub-sample of 1089 households, the aggregate poverty measures are reported in Table 9.

Because all of the measures have been constructed in constant-wellbeing equivalent form, with an identical social aggregation function ${ }^{12}$ applied, the differences are entirely due to differences in the trajectory orderings embodied by the various measures. The

\footnotetext{
${ }^{11}$ Following, for example, the work of Carter \& Barrett (2006).

${ }^{12}$ Squared poverty gap $P_{2}$ (Foster et al. 1984), reflecting sensitivity to depth of poverty, or inequality among the poor.
} 
Table 9: Aggregate poverty measures (naïve application)

\begin{tabular}{|l|r|}
\hline Measure & Value \\
\hline$P_{\mathrm{F}}$ & 0.03310 \\
$P_{\mathrm{G}}$ & 0.02556 \\
$P_{\mathrm{FS}}$ & 0.03937 \\
$P_{\mathrm{PQ}}$ & 0.05322 \\
\hline
\end{tabular}

chronicity-sensitive measures $P_{\mathrm{F}}$ and $P_{\mathrm{G}}$ evaluate the degree of poverty as less than the non-decreasing compensation measures $P_{\mathrm{FS}}$ and $P_{\mathrm{PQ}}$. This makes sense intuitively, as the normalisation means that all of the measures will evaluate in a similar way trajectories of broadly similar wellbeing levels, but the non-decreasing compensation measures will evaluate as relatively worse trajectories of fluctuating wellbeing levels.

The non-decreasing compensation measures $P_{\mathrm{FS}}$ and $P_{\mathrm{PQ}}$ are now applied to the trajectories of modelled wellbeings discussed in section 4 above. The time periods are now the eleven years spanned by the survey, 1994-2004; results are reported in Table 10.

Table 10: Intertemporal poverty

\begin{tabular}{|l|rr|}
\hline Measure & $P_{\mathrm{FS}}$ & $P_{\mathrm{PQ}}$ \\
\hline Model A (linear interpolation) & 0.02577 & 0.03594 \\
\hline Model B (hh-specific trend) & 0.02500 & 0.03459 \\
Model Bvar & 0.03245 & 0.04532 \\
\hline Model C (AR(1) with HH FE) & 0.02807 & 0.03673 \\
Model Cvar & 0.03920 & 0.05622 \\
\hline Model D (AR(1) with PA trend and HH FE) & 0.02573 & 0.03660 \\
Model Dvar & 0.03385 & 0.04970 \\
\hline
\end{tabular}

In general it may be observed that evaluating intertemporal poverty having explicitly modelled wellbeing in the years in which it was not observed gives results that are lower than if poverty were evaluated using just the years in which wellbeing was observed. ${ }^{13}$ In fact, the results are remarkably close to the results obtained by the 'chronic' poverty measures $P_{\mathrm{F}}$ and $P_{\mathrm{G}}$. This demonstrates that despite their theoretical limitations, they may serve as a good proxy for a two-stage analysis such as that carried out here, in which the evolution of wellbeing over time is explicitly modelled before intertemporal poverty is evaluated. However, this reflects different normative judgements from those apparently inherent in the 'chronic' measures, so I argue that it is better to separate the normative and positive exercises in order to maintain conceptual clarity.

It was established in section 4 that model B (household-specific time trends) had the best predictive power. The version without added variation underestimated variance and would thus tend to underestimate poverty while the version with added variation would tend to overestimate poverty. Focussing on the results obtained for model $\mathrm{B}$, we may be confident that the 'true' degree of intertemporal poverty according to $P_{\mathrm{FS}}$ is between 0.0250 and 0.0324 , while the 'true' degree of intertemporal poverty according to $P_{\mathrm{PQ}}$ is between 0.0346 and 0.0453 . In each case it is clear that the naïve application of the measures overestimated poverty in the sample.

\footnotetext{
${ }^{13}$ Note that this is not a purely mechanical effect, as all measures are normalised to avoid sensitivity to number of periods.
} 


\section{Concluding Remarks}

In this study I have explored an apparent paradox in the normative foundations for chronic and intertemporal poverty measures. Measures that reflect particular aversion to chronicity of poverty cannot also reflect particular aversion to fluctuations in the level of poverty (or wellbeing) when poverty is intense, yet good arguments are made in favour of each of these properties.

I suggest that the paradox may be resolved by recognising the incomplete nature of the information available to the poverty analyst. Particular aversion to chronicity of poverty may then be rationalised if the poverty analyst implicitly predicts that an individual observed to experience persistent poverty will continue to experience poverty in periods for which data is not available. The issue may then be addressed by separating the normative exercise of evaluation from a positive exercise of modelling and prediction. Intertemporal measures that embody particular aversion to fluctuations are more appropriate for the normative evaluation of poverty over time, but they should be applied with care when information is incomplete, for example when the poverty analyst cares about future as well as observed wellbeing. In that case an appropriate modelling exercise should be carried out explicitly, and combined with the normative exercise of evaluation.

I illustrate this proposal by application to panel data from rural Ethiopia, covering the period 1994-2004. Several dynamic models are proposed and estimated; a simple model of household-specific trends is found to give the best predictions of future wellbeing levels. Appropriately normalised measures of intertemporal poverty (embodying particular aversion to fluctuations) are applied to the predicted and observed trajectories of wellbeing and results are found to differ substantially from naïve application of the measures to observed periods only. Interestingly, the results obtained are quite similar to those found by naïve application of the measures that embody particular aversion to chronicity. This suggests that the 'chronic' poverty measures may serve as a good proxy for intertemporal poverty in a way that reflects different normative judgements from those apparently inherent in the measures. Nevertheless, I argue that it is better to separate the normative and positive exercises in order to maintain conceptual clarity.

In further work it would be interesting to explore with data from other countries whether the observed congruence between naïve application of the 'chronic' poverty measures and the two-stage approach proposed in this paper is a more general phenomenon.

\section{Acknowledgements}

The data used in the study are from the Ethiopian Rural Household Surveys, conducted by the International Food Policy Research Institute in collaboration with the Economics Department, Addis Ababa University (Economics/AAU) and the Centre for the Study of African Economies (CSAE), University of Oxford. The funding for the survey was provided by the UK Economic and Social Research Council (ESRC); Swedish International Development Agency (SIDA); United States Agency for International Development (USAID); and the World Bank. The PA-specific poverty lines and the household consumption aggregates used in this study were constructed by Stefan Dercon, University of Oxford, and extended by Catherine Porter, Heriot-Watt University. I am grateful to them for helpful discussions as well as the use of these data. The editor and an anonymous referee gave very helpful comments. Any errors are entirely my own responsibility. 


\section{References}

Baulch, B. (2011), Household panel data sets in developing and transition countries, Annotated bibliography, Chronic Poverty Research Centre. Version 2.

URL: http://www.chronicpoverty.org/uploads/publication_files/Annotated_Listing_of_Panel_Datasets

Baulch, B. \& Hoddinott, J. (2000), 'Economic mobility and poverty dynamics in developing countries', Journal of Development Studies 36(6), 1.

Bossert, W., Chakravarty, S. \& D'Ambrosio, C. (2012), 'Poverty and time', Journal of Economic Inequality 10(2), 145-162. 10.1007/s10888-011-9175-2.

URL: http://dx.doi.org/10.1007/s10888-011-9175-2

Calvo, C. \& Dercon, S. (2009), Chronic poverty and all that, in T. Addison, D. Hulme \& R. Kanbur, eds, 'Poverty Dynamics', Oxford University Press, Oxford, pp. 29-58.

Carter, M. R. \& Barrett, C. B. (2006), 'The economics of poverty traps and persistent poverty: An asset-based approach', Journal of Development Studies 42(2), 178 - 199.

Chen, S. \& Ravallion, M. (2008), The developing world is poorer than we thought, but no less successful in the fight against poverty, Technical report, World Bank.

Dercon, S. (2004a), 'Growth and shocks: evidence from rural Ethiopia', Journal of Development Economics 74(2), 309-329.

Dercon, S. (2004b), Insurance against poverty, Studies in development economics, Oxford University Press, Oxford.

Dercon, S. (2006), 'Economic reform, growth and the poor: Evidence from rural ethiopia', Journal of Development Economics 81, 1-24.

Dercon, S., Gilligan, D. O., Hoddinott, J. \& Woldehanna, T. (2009), 'The impact of roads and agricultural extension on consumption growth and poverty in fifteen ethiopian villages', American Journal of Agricultural Economics 91(4), 1007-1021.

Dercon, S. \& Krishnan, P. (1998), Changes in poverty in rural ethiopia 1989-1995: Measurement, robustness tests and decomposition, Technical Report WPS/98-7, Centre for the Study of African Economies.

Dercon, S. \& Krishnan, P. (2000), 'In sickness and in health: Risk sharing within households in rural ethiopia', Journal of Political Economy 108(4), 688.

Dercon, S. \& Shapiro, J. S. (2007), Moving on, staying behind, getting lost: Lessons on poverty mobility from longitudinal data, in D. Narayan \& P. L. Petesch, eds, 'Moving out of Poverty: Cross-disciplinary Perspectives', Vol. 1, World Bank.

Dutta, I., Roope, L. \& Zank, H. (2013), 'On intertemporal poverty measures: the role of affluence and want', Social Choice and Welfare 41(4), 741-762.

Ferreira, F. H. G., Chen, S., Dabalen, A. L., Dikhanov, Y. M., Hamadeh, N., Jolliffe, D. M., Narayan, A., Prydz, E. B., Revenga, A. L., Sangraula, P., Serajuddin, U. \& Yoshida, N. (2015), A global count of the extreme poor in 2012 : data issues, methodology and initial results., Policy Research working paper WPS 7432, World 
Bank Group, Washington, D.C.

URL: $\quad$ http://documents.worldbank.org/curated/en/360021468187787070/A-globalcount-of-the-extreme-poor-in-2012-data-issues-methodology-and-initial-results

Foster, J. E. (2009), A class of chronic poverty measures, in T. Addison, D. Hulme \& R. Kanbur, eds, 'Poverty Dynamics: Interdisciplinary Perspectives', Oxford University Press, Oxford, pp. 59-76.

Foster, J. E. \& Santos, M. E. (2013), Measuring chronic poverty, in G. Betti \& A. Lemmi, eds, 'Poverty and Social Exclusion: New Methods of Analysis', Routledge Advances in Social Economics, Routledge, Abingdon, UK, pp. 143-165.

Foster, J., Greer, J. \& Thorbecke, E. (1984), 'A class of decomposable poverty measures', Econometrica 52(3), 761-766.

Foster, J., Greer, J. \& Thorbecke, E. (2010), 'The foster-greer-thorbecke (fgt) poverty measures: 25 years later', Journal of Economic Inequality 8(4), 491-524.

Gaiha, R. \& Deolalikar, A. B. (1993), 'Persistent, expected and innate poverty: estimates for semi-arid rural south india, 1975-1984', Cambridge Journal of Economics $\mathbf{1 7}(4), 409-421$.

Gradin, C., Del Rio, C. \& Canto, O. (2011), 'Measuring poverty accounting for time', Review of Income and Wealth 58(2), 330-354.

Jalan, J. \& Ravallion, M. (2000), 'Is transient poverty different? evidence for rural China', Journal of Development Studies 36(6), 82.

Porter, C. (2008), Analysing Welfare over Time: Three Approaches for Rural Ethiopia, 1984-2004, PhD thesis.

Porter, C. (2010), 'Safety nets or investment in the future: Does food aid have any longterm impact on childrens' growth?', Journal of International Development 22, 11341145 .

Porter, C. \& Quinn, N. N. (2012), 'Normative choices and tradeoffs when measuring poverty over time'.

Porter, C. \& Quinn, N. N. (2013), Measuring intertemporal poverty: Policy options for the poverty analyst, in G. Betti \& A. Lemmi, eds, 'Poverty and Social Exclusion: New Methods of Analysis', Routledge Advances in Social Economics, Routledge, Abingdon, UK, pp. 166-193.

Townsend, R. M. (1994), 'Risk and insurance in village india', Econometrica: Journal of the Econometric Society 62(3), 539-591. 